\title{
JPAM
}

\section{Place-Based Advantages in Entrepreneurship: How Entrepreneurial Ecosystem Coordination Reduces Transaction Costs}

\author{
Philip T. Roundy \\ Department of Marketing and Entrepreneurship, University of Tennessee (Chattanooga) \\ Dutch Fayard \\ Department of Accounting, University of Tennessee (Chattanooga)
}

\begin{abstract}
Author Note
Philip T. Roundy https://orcid.org/0000-0002-4262-5274

We have no known conflict of interest to disclose.

Correspondence concerning this article should be addressed to Philip T. Roundy, Dept. of Marketing and Entrepreneurship, 615 McCallie Avenue, Chattanooga, TN, 37403. Email: philip-
\end{abstract} roundy@utc.edu 


\begin{abstract}
Academics and practitioners are increasingly lauding the economic and community benefits of entrepreneurial ecosystems: the inter-related forces that promote and support entrepreneurship in geographic areas. Most researchers examining entrepreneurial ecosystems have sought to identify their core attributes rather than isolating the concrete mechanisms by which entrepreneurial ecosystems influence entrepreneurs. We address this omission in ecosystems research by theorizing about a specific set of economic forces through which ecosystems influence the entrepreneurship process: cost-reduction mechanisms. We integrate and extend insights from transaction cost economics and develop a framework for understanding the costreducing effects of ecosystems on entrepreneurial activities. We synthesize the fragmented research on entrepreneurial ecosystem coordination and theorize that as coordination increases three types of costs - search, negotiation, and enforcement - decrease, which improves ecosystem participants' ability to engage in entrepreneurship. Our theorizing contributes to research at the management and entrepreneurship interface and produces actionable insights for entrepreneurs and ecosystem builders.
\end{abstract}

Keywords: Entrepreneurial ecosystem, Start-up communities, Regional entrepreneurship, Small business management, New venture creation, Transaction cost economics, Economic development, Community entrepreneurship

\title{
Place-Based Advantages in Entrepreneurship: How Entrepreneurial Ecosystem Coordination Reduces Transaction Costs
}

There is growing acknowledgment that entrepreneurship - the pursuit of innovative opportunities to mobilize resources and create value (Shane and Venkataraman, 2000) - is not a solitary activity but requires a system of interconnected stakeholders, including customers, investors, mentors, suppliers, and employees (Cavallo, Ghezzi, \& Balocco, 2019).

Entrepreneurship also occurs within distinct contexts that are comprised of unique economic, social, and cultural forces (Welter, 2011). To reflect the place-based nature of entrepreneurship, scholars and practitioners are now emphasizing entrepreneurial ecosystems, the interrelated set of individuals, organizations, institutions, values, and artifacts that produce entrepreneurship in geographic areas (Brown \& Mason, 2017; Kuckertz, 2019; Malecki, 2018; Roundy, Brockman, \& Bradshaw, 2017; Spigel \& Harrison, 2018).

Entrepreneurial ecosystems studies have examined how entrepreneurs' ability to pursue opportunities and create value depends on a complex set of factors, including early-stage funders, support organizations (e.g., incubators and accelerators), entrepreneurial human capital, stories of successful entrepreneurs, and cultural values that encourage entrepreneurship and cooperation (Isenberg, 2010; Neck, Meyer, Cohen, \& Corbett, 2004; Roundy, 2016; Spigel, 2017). However, researchers and practitioners have been slow to identify the specific mechanisms, operating at the individual, organizational, and ecosystem levels, through which entrepreneurial ecosystems influence entrepreneurship (Nicotra, Romano, Del Giudice, \& Schillaci, 2018). As a result, entrepreneurial ecosystems research remains in a nascent stage of 


\section{PLACE-BASED ADVANTAGES IN ENTREPENEURSHIP}

theory development, is often descriptive rather than theoretical, and does not emphasize the linkages between ecosystem forces and entrepreneurial activities (Stam \& Spigel, 2016).

Entrepreneurial ecosystems (EEs) research has made strides in understanding why some cities, regions, and countries, such as Tel Aviv, Silicon Valley, Bangalore, and Taiwan, are "hotbeds" of entrepreneurial activity, while others struggle to support thriving entrepreneurship communities (Bala Subrahmanya, 2017; Engel, 2015; Schäfer \& Henn, 2018). Scholars are also beginning to study the processes involved in EE emergence, evolution, management, and measurement (Auerswald \& Dani, 2017; Autio \& Levie, 2017; Mack \& Mayer, 2016; Miles \& Morrison, 2019; Roundy, Bradshaw, \& Brockman, 2018; Stam, 2018). Despite the progress made by this research, scholars have only begun to tease apart the specific means by which EEs change the entrepreneurial process for ecosystem participants.

The lack of theoretical models explaining how EEs influence entrepreneurship is an important omission in ecosystems research for several reasons. Without a clear understanding of the mechanisms driving entrepreneurial ecosystems' influence, it is difficult to evaluate the potency of different ecosystems or to understand why some regions are more (or less) successful than others in promoting and supporting entrepreneurial activities. For instance, it is not clear why there are differences in the vitality of EEs across high-income, emerging, and developing economies and between large and small cities (cf. Roundy, 2017b). Regional variations in the effectiveness of EEs and the intensity of entrepreneurial activities are important because they are associated with regional differences in the spillover benefits of entrepreneurship, such as job creation, financial independence, psychological empowerment, technological advancement, and economic development (Audretsch \& Keilbach, 2008). Furthermore, without a framework that teases apart the direct effects of EEs on participants, there is not a granular understanding of how EE components influence entrepreneurial activities and, thus, which components should be prioritized for scholars, ecosystem builders, and resource providers.

To address the lack of attention to the direct linkages between entrepreneurial ecosystems and entrepreneurial activities, we integrate and extend insights from transaction cost economics and theories of organizational costs (Coase, 1937; Ketokivi \& Mahoney, 2016; Williamson, 1985) and develop a framework for explaining the cost-reducing effects of EEs on entrepreneurs and their ventures. This theoretical framework explores the question: how do the components of entrepreneurial ecosystems influence the costs of entrepreneurial activities and what types of costs are influenced? We theorize that EEs are a type of meta-organization - a network of individuals and organizations not bound by formal employment relationships but united by collective, system-level characteristics (cf. Gulati, Puranam, \& Tushman, 2012). As metaorganizations, entrepreneurial ecosystems influence three categories of transaction costs that entrepreneurs incur during the creation and operation of new ventures. To understand these effects, we synthesize prior work on the coordinating effects of ecosystems and define entrepreneurial ecosystem coordination as the degree to which participants engage in explicit activities to develop and support an ecosystem. We argue that as an ecosystem's coordination increases its cost-reducing effects increase. In coordinated ecosystems, entrepreneurs have lower costs to engage in market transactions, including the costs to search for, negotiate, and enforce 


\section{PLACE-BASED ADVANTAGES IN ENTREPENEURSHIP}

contracts. In contrast, in less coordinated EEs, entrepreneurs' costs to found and operate their ventures are higher.

The proposed model and the theory underpinning it represent contributions to the entrepreneurship literature by identifying a set of specific mechanisms through which EEs influence entrepreneurs' decisions, the functioning of their ventures, and their likelihood of success. Our model explains one reason why ecosystems have different levels of entrepreneurial activities. In making these contributions, we focus on micro-level (i.e., entrepreneur- and venture-level) effects, rather than macro-level (i.e., ecosystem-level) outcomes (e.g., Cunningham, Menter, \& Wirsching, 2019). By doing so, we avoid a limitation of the "macro perspective," which is that it does "not address the attribution of outcomes, costs, and benefits which is one of the main criticisms of entrepreneurial ecosystems" (Cunningham et al., 2019: 4).

The paper is structured as follows. In the next section, we review the literature on which we build our theory: transaction cost economics and entrepreneurial ecosystems. In reviewing this work, we emphasize the key omissions in EEs research that can be addressed by our proposed model of ecosystem coordination. We then develop a theory about how the characteristics of EEs influence the costs associated with entrepreneurial activities. Finally, we discuss the implications of our theorizing for scholars and practitioners and suggest several avenues for future research.

\section{Literature Review}

\section{Transaction Cost Economics}

Transactions, the unit of analysis in transaction cost economics (TCE), are transfers of goods and services between buyers and sellers (Williamson, 1985). Transaction costs are the costs of finding, arranging, and making these transfers and are a market "friction" (Coase, 1937; Williamson, 1981). Transaction costs are incurred while participating in markets and are contrasted with the physical costs of goods and services (i.e., production costs) (Hamet \& Michel, 2018). Transaction costs' importance stemmed from Coase's realization that "[there is] a factor of production, management, whose function [is] to coordinate. Why [is management] needed if the pricing system provided all the coordination necessary?" (1992, p. 715). Answering this question clarified the unique and complementary roles played by management within organizations and the market pricing system and generated transaction cost economics' central claim: when individuals make transactions they seek to minimize transaction costs (David \& Han, 2004). Examining how transaction costs are minimized creates insights into why firms exist as organizational forms, why the economy is not organized as a single firm, and why firms vertically integrate (Williamson, 1981).

\section{Types of transaction costs}

Scholars have identified several types of transaction costs, which can be grouped into three general categories - contact, contract, and control costs - based on the point in a transaction in which costs are incurred (Carmel \& Nicholson, 2005). Contact costs are the costs 


\section{PLACE-BASED ADVANTAGES IN ENTREPENEURSHIP}

of finding an appropriate exchange partner (e.g., a customer or supplier) and include search and information costs (den Butter \& Linse, 2008). Contract costs are from bargaining, coordinating, and constructing the contract governing a transaction (e.g., establishing an R\&D cooperation agreement) (Yang, Ho, \& Chang, 2012). Control costs are incurred after a contract is negotiated and involve the observation and enforcement costs of ensuring that an exchange partner does not renege on a contract, act opportunistically, or fail to meet obligations (Chen, 2010). In sum, transaction costs are the costs involved in searching for, negotiating, and monitoring an agreement to exchange goods or services (Williamson, 1985).

\section{Transaction cost economics and entrepreneurship}

Transaction cost economics is implicitly tied to entrepreneurship through one of Coase's (1937, p. 390) fundamental questions, "why and under what conditions should we expect firms to emerge?" Responding to arguments in neoclassical economics about the efficiency of markets in organizing transactions through the price mechanism, Coase and other transaction cost theorists sought to identify the conditions in which entrepreneurs create organizations rather than contracting work and relying solely on the external price mechanism. Transaction cost economics contends that firms organize tasks "in-house" if the transaction costs of using the market mechanism are high (Coase, 1937). This suggests that entrepreneurs create firms because there are circumstances in which organizations are better at economizing on transaction costs than markets - that is, in some cases, firms facilitate intra-organizational transactions at a cost that is lower than in the marketplace.

One of the main activities of entrepreneurs is finding new ways to avoid or reduce transaction costs (Chen, 2010). Entrepreneurs attempt to limit transaction costs to improve their profit margins, a key success metric influencing new venture survivability, and to attract resources from stakeholders (cf. Delmar, McKelvie, \& Wennberg, 2013; Michael, 2007). Scholars use the transaction cost economics lens to examine several phenomena including entrepreneurs' appraisals of venture capitalists' external and internal support, decisions to ally with partners, and choices to outsource production (Halim, Ahmad, Ho, \& Ramayah, 2017; Khanin \& Turel, 2016). Scholars also find important contextual differences in transaction costs (e.g., costs in high-income versus emerging economies; cf. Ahmad \& Etudaiye-Muhtar, 2017).

However, transaction costs and entrepreneurship research have been slow to consider how contextual differences, including geographic and place-based characteristics, influence entrepreneurs' costs (cf. Welter, 2011). As a result, research at the intersection of entrepreneurship and transaction cost economics has not been extended to the entrepreneurial ecosystem and, as such, has not considered how the ecosystem of place-based forces influence entrepreneurs' transaction costs. Studies have begun to hint that EEs influence entrepreneurial costs (e.g., Theodoraki, Messeghem, \& Rice, 2018) and, thus, improve entrepreneurs' performance; however, a theoretical model has not been proposed to explain these effects and to tie them to specific EE characteristics. In the sections that follow, we argue that important insights are gained by examining how coordinated EEs present entrepreneurs with a unique set of transaction cost-reducing mechanisms. We lay the foundations for these arguments in the next 


\section{PLACE-BASED ADVANTAGES IN ENTREPENEURSHIP}

section where we argue that it is appropriate to apply transaction cost economics to EE dynamics and introduce the distinction between coordinated and uncoordinated ecosystems.

\section{What makes entrepreneurial ecosystems unique and vibrant?}

There are important differences between EEs and related phenomena involving groups of connected firms. EEs differ from the more general concept of "business ecosystems" (or "innovation ecosystems"; e.g., Adner, 2017) in that EEs have boundaries corresponding to specific geographic areas (e.g., cities or regions) whereas business ecosystems do not have spatial boundaries (e.g., Apple's hardware ecosystem). EEs also differ from clusters and industrial districts (e.g., Feldman, Francis, \& Bercovitz, 2005), which are subsets of firms in business communities that share a similar focus, such as specializing in the same technologies. Although these phenomena are similar to EEs in that they are geographically bounded, EEs are distinct in that they do not focus on a specific technology and can contain ventures from any industry or sector. Finally, EEs are also different from "entrepreneurial enclaves" (e.g., Braymen \& Neymotin, 2014; Li, Isidor, Dau, \& Kabst, 2018), which represent groups of firms united by entrepreneurs from specific ethnic groups or by co-located communities of immigrant entrepreneurs. In contrast, studies of EEs focus on all entrepreneurial actors within a geographic area (typically, a city or sub-national region). Thus, an entrepreneurial ecosystem is more encompassing than a specific entrepreneurial enclave and may contain multiple entrepreneurial enclaves. Finally, unlike other phenomena (e.g., "innovation districts"), entrepreneurial ecosystems emerge through a combination of self-organization (i.e., non-controlled market mechanisms) and purposive, ecosystem-building; that is, EEs arise from both "bottom-up," market-driven processes and "top-down" leadership from individuals actively attempting to develop the ecosystem (Miles \& Morrison, 2019; Roundy, 2019).

Ecosystems scholars have attempted to identify the key elements and characteristics of vibrant EEs - geographic areas that encourage and sustain high levels of entrepreneurial activity (Stam \& Van de Ven, 2019). Vibrant EEs are receiving heightened attention because they are thought to be contexts that are ripe for entrepreneurial activity and in which entrepreneurs have a greater likelihood of creating successful ventures. For example, case studies of EEs, like Boulder, Colorado (USA), have found that vibrant EEs typically have a diverse set of components that create an environment ripe for entrepreneurship (e.g., Neck et al., 2004; Spigel, 2017). These components include: communities of entrepreneurs creating a variety of new ventures (from traditional, organic-growth businesses to aggressive growth ventures), early-stage investors, local customers, compelling narratives of entrepreneurial successes, support organizations, dense networks connecting participants, and cultures supportive of entrepreneurial risk-taking (Isenberg, 2011; Kenney \& Von Burg, 1999).

Vibrant EEs also exhibit coherence - that is, there are EE participants engaging in the same general entrepreneurial activities, such as founding new ventures, experimenting with business models, acquiring early customers, testing new technologies, and seeking to improve the local community (Roundy et al., 2018). These parallel activities cause EE participants to become entrained (cf. Pérez-Nordtvedt, Payne, Short, \& Kedia, 2008) to the same schedules and patterns of activity. EE participants also develop coherence in the way they think about 


\section{PLACE-BASED ADVANTAGES IN ENTREPENEURSHIP}

entrepreneurship from going through common training programs and experiences offered by entrepreneurial support organizations like incubators and accelerators (Roundy, 2017a).

However, for an EE to be vibrant, we argue, it is not sufficient for it simply to contain a diverse set of components or for the activities of EE participants to cohere (i.e., for participants to be engaged in many of the same activities). In addition to these characteristics, there must also be EE coordination: the degree to which EE participants engage in deliberate efforts to build, develop, and support the EE. In coordinated EEs, participants make explicit attempts to promote and sustain entrepreneurial activities in their geographic areas. In other words, there are explicit efforts to work "on" the ecosystem. The result is that an EE emerges and is maintained by participants who are no longer atomistic and autonomous but instead are part of a loosely connected meta-organization, the entrepreneurial ecosystem.

\section{Entrepreneurial ecosystem coordination}

Coordination has been identified as a foundation for business ecosystems (Adner \& Kapoor, 2010). In studies of entrepreneurial ecosystems, coordination is alluded to but typically not defined. For instance, Kuratko and colleagues (2017: 120) refer to EEs as "coordinated attempts to establish environments that are conducive to the probabilities of success for new ventures." Stam (2015: 1765) conceptualized an EE as "a set of interdependent actors and factors coordinated in such a way that they enable productive entrepreneurship" (emphasis added). However, very few studies focus on the role that coordinating activities play in ecosystems.

An exception is a study by Miles and Morrison (2019) focusing on the Research Triangle EE in North Carolina (USA). They found that coordinating activities, such as network development and knowledge brokering, were key actions of ecosystem leadership. Another explicit examination of EE coordination is found in Spigel's (2016) study of the Edinburgh, Scotland EE. Spigel defines coordination as a support service provided by some entrepreneurial support organizations (e.g., incubators), which involves "creating [a] community of entrepreneurial actors within a region [and] helping to bring together different parties to develop new programs and agendas" (151). Coordination consists of "organizations that attempt to build and sustain an entrepreneurial community and ensure cooperation between different bodies." (151). Although coordination features prominently in Spigel's study of the Edinburgh EE, he primarily focused on how support organizations are coordinated and engage in coordinating activities. He did not develop a more general theory of EE coordination and its effects on EE participants. Likewise, EE scholars have not sought to identify the specific linkages between coordination as an ecosystem-level characteristic and the entrepreneurial processes of EE participants. To theorize about such linkages requires synthesizing prior research on coordination and clarifying its specific activities.

\section{What is EE coordination?}

Building on prior studies that acknowledge (either explicitly or implicitly) the importance of EE coordination, we propose that coordination involves three types of activities-cognitive, social, and cultural - that participants engage in to build, develop, and support their EEs. These 


\section{PLACE-BASED ADVANTAGES IN ENTREPENEURSHIP}

activities help to create an organized and interdependent system of entrepreneurs and EE participants rather than a loose collection of semi-autonomous, independent agents.

First, coordination includes activities that establish the EE as a distinct entity in the cognitions of EE participants. Cognition-focused activities draw attention to an EE and reify its existence in participants' minds. For example, Spigel (2016) found that there was a subset of entrepreneurial support organizations in the Edinburgh EE who did "not provide direct services to entrepreneurs at all but instead focus[ed] on coordinating the larger entrepreneurial ecosystem" (156). Such activities create a shared belief that an EE exists, which establishes it as a distinct object of attention and serves as the basis for participants' interactions, commitment to the EE, and shared perceptions about their ecosystem (Goswami et al., 2018).

EE coordination also has a social component. In coordinated EEs, there are dense and highly connected social networks among entrepreneurs, investors, support organizations, and other participants, which help EE participants become aware of others in the system and, in general, represent the ecosystem's social structure (Theodoraki et al., 2018). An EE's networks are created and strengthened through spontaneous interactions at EE activities and events (i.e., "collisions"; Nylund \& Cohen, 2017) and by the deliberate efforts of "entrepreneurial dealmakers" - actors who help to "coordinate the right match among the various players in the ecosystem" (Brown and Mason, 2017; Colombo et al., 2019; Goswami et al., 2018: 117). Dense social networks are key to EE coordination because they transmit information and other resources among ecosystem participants and improve the organization of the ecosystem (Neumeyer, Santos, Caetano, \& Kalbfleisch, 2019).

Finally, coordination involves the extent to which EE participants share common values, norms, simple rules and narratives. These aspects of coordination indicate the degree to which EE participants share a common culture, which causes them to interact with one another and to exhibit cooperative, prosocial behaviors in their entrepreneurial activities. For example, norms such as "give to the EE before taking," "help others," and "favor cooperation or competition with other ecosystem participants" (Feld, 2012), strengthen the interdependence of EE participants and help to organize their interactions.

The proposed conceptualization of EE coordination suggests that EEs can be arrayed based on their degree of coordination. In some EEs, there will be a subset of EE participants who are actively involved in deliberate efforts to build, develop, and support entrepreneurship and the EE. In contrast, in other EEs, entrepreneurial activities and investments in the entrepreneurial community will be haphazard or non-existent. Examples from opposite ends of the EE coordination continuum - highly uncoordinated and highly coordinated - highlight the importance of coordination for understanding differences in the vibrancy of EEs.

Uncoordinated EEs are often found in rural regions. Although rural ecosystems may not be vibrant, rural communities, like all regions, possess an EE because creating a business requires a set of interconnected forces (e.g., customers, suppliers, labor, entrepreneurshiporiented values, and institutions supporting property rights) (Korsgaard, Ferguson, \& Gaddefors, 2015). In rural regions, there may even be people engaging in the same activities, such as 
creating new businesses (i.e., there is some degree of EE coherence). However, rural EEs are often not vibrant because they lack coordination in the efforts of ecosystem participants to promote and support their ecosystems. This lack of coordination is partly a result of the absence of ecosystem "champions," individuals and organizations that explicitly draw attention to and seek to develop the entrepreneurial ecosystem (Haines, 2016). In uncoordinated EEs, entrepreneurial activities may occur but there is not a clearly identified entrepreneurship community comprised of individuals engaging in deliberate attempts to stimulate and sustain entrepreneurship. As a result, in such ecosystems, entrepreneurs may lack connections to other participants in the EE and, thus, may be unaware of other entrepreneurial activities in the ecosystem or even unaware of the EE itself.

In contrast, at the high end of the coordination continuum are large, mature EEs, like Silicon Valley and the North Carolina (USA) Research Triangle (cf. Miles \& Morrison, 2019). In these EEs, there is not only a diverse collection of participants and a high degree of EE coherence (e.g., many participants involved in the shared pursuit of venture creation), but there is also coordination. Participants are cognizant of the ecosystem as an entity, they are highly connected, and there is a subset of participants who make deliberate attempts to work together to promote and support entrepreneurial activities by strengthening and developing the ecosystem. That is, in coordinated EEs, there is a diverse entrepreneurial community comprised of participants engaging in cohering activities and explicit investments are being made to build and strengthen this community. As we describe in the next section, an important consequence of EE coordination is that it reduces several types of transaction costs.

\section{Theory Development}

\section{Entrepreneurial Ecosystem Coordination and Search Costs}

Search is involved in all stages of entrepreneurship (e.g., Fiet, Norton, \& Clouse, 2013). Entrepreneurs must search for information about how to incorporate businesses, acquire necessary permits, and find capital - all of the information that is necessary to found and operate new organizations. In pursuing opportunities, entrepreneurs must also search for viable business models, often through trial and error, which involves honing their value proposition (cf. Kerr, Nanda, \& Rhodes-Kropf, 2014). During this process, entrepreneurs search for customers and refine their business models by getting feedback on consumers' preferences and demands. The search for a viable business model is a nonlinear, highly iterative process whereby an entrepreneur seeks feedback on ideas and prototypes (Goldsby, Kuratko, Marvel, \& Nelson, 2017). While iterating, entrepreneurs may search for feedback from mentors or learn vicariously by observing competitors' actions (Lévesque, Minniti, \& Shepherd, 2009). This process is costly in terms of entrepreneurs' attention and the time spent searching for information and for the capital needed to build early versions of products. In coordinated EEs, however, entrepreneurs do not need to devote as much time to search for several reasons.

First, coordinated EEs are comprised of dense and cohesive social networks connecting entrepreneurs, investors, and support agents (Motoyama \& Knowlton, 2017). Networks foster information transfer and allow information to be located and exchanged efficiently from one 


\section{PLACE-BASED ADVANTAGES IN ENTREPENEURSHIP}

member of a communicating population to another (de Klerk \& Saayman, 2012). Thus, when aspiring entrepreneurs search for information in a coordinated ecosystem, if they can gain access to the EE's social network, their search costs will decrease because of their position in the flow of information.

Entrepreneurial support organizations play a critical role in ecosystem coordination and in decreasing search costs (Roundy, 2017a; Spigel, 2016). Support organizations not only equip early-stage entrepreneurs with skills but, by providing information about the ecosystem, they help entrepreneurs to develop mental maps of the ecosystem and its participants, which allows them to find information in the ecosystem more efficiently. Support organizations also improve the ecosystem's social network by connecting entrepreneurs to resource providers, such as mentors, investors, and customers (Spigel, 2016). In addition, support organizations often direct entrepreneurs to other necessary services, including legal, accounting, and information technology services (Goswami, Mitchell, \& Bhagavatula, 2018). By serving as the connector between entrepreneurs and the information and other resources they seek, support organizations increase the ease of finding and acquiring information and reduce the time devoted to search.

Coordinated ecosystems also reduce entrepreneurs' costs to search for viable business models through frequent events, such as networking meet-ups and pitch competitions, where entrepreneurs receive feedback on their ideas from investors, prospective customers, and other entrepreneurs. In addition to being forums for critical early feedback, such events are also opportunities for entrepreneurs to be exposed to cultural artifacts like the shared narratives of the ecosystem (e.g., local entrepreneurship success stories). The learning opportunities provided by narratives allow entrepreneurs to avoid some of the costs of direct learning (Roundy, 2016). Through narratives, entrepreneurs learn vicariously from the successes and failures (Dias \& Teixeira, 2017) of other entrepreneurs and, thus, are able to hone their business models faster and with less direct search and experimentation. The interactions that occur at events also expose entrepreneurs to the ecosystems' cultural norms about cooperation and sharing information.

While building their ventures, entrepreneurs often need to search for new members of the founding team, for early-stage employees, or for suppliers. Search costs for these types of resources are reduced as EE coordination increases. In coordinated ecosystems, it is easier for entrepreneurs to find EE-specific human capital, which means that entrepreneurs do not have to extensively search for co-founders and other stakeholders with entrepreneurship expertise. For instance, in a study of the Waterloo, Canada EE, Spigel (2017) found that entrepreneurs were able to access a large pool of skilled workers who were accustomed to the challenges of working at startups and willing to reduce their upfront labor costs in exchange for future revenue sharing.

Collectively, the impact of coordinated EEs on entrepreneurs' search costs suggests:

Proposition 1. As entrepreneurial ecosystem coordination increases, entrepreneurs' search costs decrease. 


\section{Entrepreneurial Ecosystem Coordination and Negotiation Costs}

Beyond the costs of searching for transaction partners, there are also costs involved in processing the information obtained from search and then negotiating contracts to govern transactions. For instance, in addition to the costs incurred searching for investment, after entrepreneurs identify an interested investor they experience another set of costs associated with evaluating investors and deciding if they should enter investment relationships (Hochberg, 2016). Evaluating investors may require gathering more information about investors' motives, track records, and desired exit horizons from additional meetings or through conversations with other EE members.

After information about desired resources has been processed, there are costs to entrepreneurs of constructing contracts to obtain these resources (Yang et al., 2012). For instance, if an entrepreneur determines that a prospective investor is a fit, the entrepreneur has additional costs (e.g., bargaining, legal fees) associated with constructing a contract outlining the key points in the transaction and the terms of the investment (e.g., the investment amount, the equity exchanged, the possibility for follow-on investment; Amatucci \& Swartz, 2011). Some transactions, such as entering a lease agreement, involve creating a formal, typically written, contract between two parties. Other transactions, such as informal resource exchanges (e.g., entrepreneurs agreeing to assist in the development of other entrepreneurs' business ideas in exchange for help developing their ventures), usually do not involve an explicit, written contract, although there is often an implicit social contract guiding the relationship (Rousseau, 1989). With formal and informal contracts, entrepreneurs incur costs from negotiating the contracts and making decisions about if the contracts should be accepted.

In coordinated EEs, entrepreneurs' negotiation-related transaction costs are reduced. First, at the information processing stage, as EE coordination increases, costs are reduced because entrepreneurs do not need to store and individually process all of the information necessary to make transactions. Entrepreneurs can "outsource" some of their information processing and rely on knowledge obtained through their network connections with other EE members. For instance, in the example of an entrepreneur seeking investment, as EE coordination increases, an entrepreneur can rely on information from the EE's network about potential investors, which reduces their costs of personally obtaining information and evaluating investors. By doing so, the entrepreneurs are relying on the collective knowledge and "transactive memory" of EE members (e.g., Heavey \& Simsek, 2017)

Second, ecosystem coordination will also reduce the costs to construct and negotiate contracts. As ecosystem coordination increases, participants are more likely to share common cultural norms and to be driven, in part, by a community logic comprised of values such as collaboration and community-building (Roundy, 2017a; Thornton et al., 2012). For EE participants who are guided by a community logic, it will make them more likely to help other EE participants because of beliefs that doing so is valuable and will strengthen the entrepreneurship community. If EE participants hold common values, like fairness, openness in transactions, and trust (cf. Muldoon, Bauman, \& Lucy, 2018), then this reduces entrepreneurs' negotiation costs because entrepreneurs can rely on informal mechanisms, such as mutual trust 


\section{PLACE-BASED ADVANTAGES IN ENTREPENEURSHIP}

and altruism, as a basis for contracts, which reduces time spent negotiating agreements. Taken together, these arguments suggest:

Proposition 2. As entrepreneurial ecosystem coordination increases, entrepreneurs' negotiation costs decrease.

\section{Entrepreneurial Ecosystem Coordination and Monitoring Costs}

Monitoring costs are a third category of transaction costs that are incurred aftermarket contracts are negotiated (Chen, 2010). Monitoring includes the costs of enforcing contracts and ensuring that contracted parties deliver what is promised and do not back out on or shirk obligations. As EE coordination increases, monitoring costs are reduced because, in coordinated ecosystems, the shared culture and densely connected participants produces an entrepreneurial community that is more likely to informally police itself. For instance, Feld (2012) describes how participants in the tight-knit Boulder EE share the same prosocial values which involves actively removing "bad apples" (i.e., members that take advantage of the community). If EE participants break formal contracts or informal norms, they are ostracized by the entrepreneurial community and not given further opportunities to participate in the ecosystem (Feld, 2012). In these situations, the community enacts social sanctions on free riders and on those not fulfilling obligations, thereby discouraging negative behaviors, such as breaking contracts. A further deterrent to such behaviors is that news of contract violations will rapidly spread among connected networks of participants, which brings violators to light. Finally, the same norms that give rise to the EE as a coordinated community (e.g., helping others, valuing others' time) limit shirking on formal and informal obligations. The result of these ecosystem forces is that entrepreneurs do not need to devote as many resources to monitoring and enforcing transaction contracts, which suggests:

Proposition 3. As entrepreneurial ecosystem coordination increases, entrepreneurs' monitoring costs decrease.

Table 1 summarizes the main arguments in our theory. 
PLACE-BASED ADVANTAGES IN ENTREPENEURSHIP

TABLE 1

The Cost-Reducing Mechanisms of Coordinated Entrepreneurial Ecosystems

Type of Transaction Cost

\section{Search costs}

The costs of identifying entrepreneurial opportunities, information, business models, customers, and investors.

\section{Negotiation costs}

The costs of evaluating transaction information, determining a price and the terms of transactions, and constructing formal and informal contracts to obtain transacted resources.

\section{Enforcement costs}

The costs of monitoring contracts and ensuring that parties deliver what is promised and do not shirk obligations.
Ecosystem Mechanisms
Main Theoretical Arguments
Dense networks foster efficient information exchange; support organizations help entrepreneurs develop mental maps of the ecosystem and serve as connectors between entrepreneurs and resources; EE events expose entrepreneurs to cultural artifacts and ecosystem values and allow entrepreneurs to receive feedback and engage in vicarious learning.
As entrepreneurial ecosystem coordination increases, entrepreneurs' search costs decrease because it is easier to find resources and resource providers.
Ecosystem networks provide access to the collective knowledge of the system; commonly held values and a community logic allow entrepreneurs to rely on informal contracting mechanisms, such as mutual trust and altruism.
As entrepreneurial ecosystem coordination increases, entrepreneurs' negotiation costs decrease because it is easier to evaluate information and construct contracts.
The entrepreneurship community engages in self-policing and enacts social sanctions for contract violations; knowledge of violations spreads rapidly through dense networks; the ecosystem is comprised of values and norms that limit breaking contracts and shirking obligations.
As entrepreneurial ecosystem coordination increases, entrepreneurs' enforcement costs decrease because community members are more likely to fulfill transaction obligations. 


\section{Discussion}

Entrepreneurial activities are increasingly promoted as mechanisms for economic growth, community development, and improved well-being (Mason and Brown, 2014). Strengthening entrepreneurial ecosystems is viewed as a potent strategy for revitalizing business communities in struggling economies, underdeveloped countries, and rural regions. However, despite assertions about the positive benefits of vibrant EEs, researchers and practitioners are not clear about how EEs influence entrepreneurial activity. Instead, the common assertion is simply that entrepreneurs benefit from "healthy start-up communities." How exactly the entrepreneurial process is made more efficient because of the forces in EEs remains under-theorized. To address this issue, we argue that, as coordinated meta-organizations, EEs can be studied through the lens of transaction cost economics, which provides a unique set of concepts and mechanisms and highlights one pathway through which EEs influence entrepreneurs' actions and activities. We propose a theoretical model to explain how EEs influence entrepreneurs during three phases of market transactions. We argue that as EE coordination increases, entrepreneurs' search, negotiation, and monitoring costs decrease. In the sections that follow, we unpack how our theory contributes to research on entrepreneurial ecosystems and transaction cost economics, produces implications for ecosystem-builders and entrepreneurs, and suggests directions for future research on entrepreneurial ecosystems.

\section{Contributions to Entrepreneurship Research}

\section{Entrepreneurial ecosystems}

By synthesizing prior research on EE coordination and by clarifying the concept, we identify an important - and foundational - difference between EEs. Scholars have struggled with if it is appropriate to classify some areas, such as rural regions and small towns, as having entrepreneurial ecosystems or if "entrepreneurial ecosystem" is a label that should be reserved only for mature entrepreneurial communities, typically in large cities, or for regions able to produce a particular type of entrepreneurship (e.g., high growth ventures) (Audretsch \& Belitski, 2017). Our theorizing suggests that it is not a question of whether a region has an entrepreneurial ecosystem, but, rather, if the ecosystem is coordinated. Wherever entrepreneurship occurs there is a system of material, social, and cultural forces (cf. Spigel, 2017) influencing it. Regions differ, however, in the extent to which entrepreneurial communities are coordinated (i.e., the degree to which they make deliberate attempts to invest in, promote, and support their ecosystems).

Despite the progress made by scholars, there is very little theoretical work to guide EE studies (Spigel \& Harrison, 2018). In this paper, we have integrated theory from transaction costs economics with entrepreneurial ecosystems. This represents a theoretical contribution to EE studies because it begins to shed light on what EEs are and why they exist. Specifically, the transaction cost economics lens suggests that EEs are a form of meta-organization that exists, in part, to decrease the transaction costs of EE participants. That is, one reason that coordinated entrepreneurial ecosystems are valuable and should be a source of academic interest and 
practitioner resources, is that they facilitate transactions associated with entrepreneurial activities at costs that are lower than in the marketplace or in geographic areas without coordinated ecosystems. In addition, our theory suggests that important insights can be gained by focusing not only on the intersection of EEs and the commonly studied processes of entrepreneurship, such as opportunity recognition and value creation, but also by focusing on the costs associated with entrepreneurial activity. Focusing on these facets of entrepreneurship has illuminated how an important function of entrepreneurial ecosystems is that they influence entrepreneurs' costs.

\section{Transaction cost economics}

The theory we develop also represents a contribution to transaction cost economics. Critics of transaction cost economics argue are that the theory often neglects that economic (and entrepreneurial) activities are embedded in social contexts (Uzzi, 1997). The theory has also be criticized for focusing primarily on dyadic transaction relationships and on the interactions between isolated exchange partners. As such, transaction cost theory has not focused on how transactions are embedded in a larger network of individuals and organizations (Uzzi, 1996). However, by using transaction cost economics to explain the functioning of EEs, we expand the boundaries of transaction cost theory and draw attention to how it can be used to understand transactions that depend on complex systems of agents, institutions, and values. We also contribute to transaction costs research by incorporating a more complete picture of the entrepreneur, beyond the conception of the entrepreneur as simply a market actor who exploits discrepancies between what is done in the market and what could be done in a firm (Jacobson, 1992). We treat the entrepreneur as a multi-faceted agent that is involved in several types of activities (e.g., pursuing opportunities, developing business models, gathering customer feedback, finding investment) and who is influenced by a complex set of economic, sociocognitive, and cultural forces, which, in turn, influence their transaction costs.

\section{Implications for Entrepreneurs and Ecosystem Builders}

The difference between coordinated and uncoordinated EEs is not merely a theoretical distinction. It has implications for practitioners seeking to build EEs. Specifically, our theory suggests that stakeholders in areas suffering from limited entrepreneurial activities or struggling to successfully promote entrepreneurial activity should assess if there is coordination in their entrepreneurial ecosystems. As we argue, having other beneficial EE characteristics, like diversity and coherence, are necessary, but not sufficient, conditions for having a vibrant entrepreneurial ecosystem. Stakeholders seeking to promote entrepreneurship should evaluate both the diversity and cohesiveness of the entrepreneurship community and the degree to which the ecosystem is actively being promoted and supported (i.e., its coordination).

Practitioners increasingly contend that creating EEs is a positive investment in their regional economies. However, beyond the belief that EEs are associated with more entrepreneurship (and the spillover benefits that entrepreneurship can produce), economic development agents are often unclear about precisely why creating a vibrant entrepreneurial ecosystem is a "good thing." We identify one specific facet of the entrepreneurship process - the minimization of transaction costs - that is improved by coordinated EEs. Ecosystem-builders 


\section{PLACE-BASED ADVANTAGES IN ENTREPENEURSHIP}

seeking resources from regional stakeholders can point to the ability of vibrant ecosystems to lower entrepreneurs' costs.

Being able to identify and assess the specific benefits provided by EEs is important because funding agencies, such as foundations and local governments, serve as resource providers to EE builders and often require resource recipients to measure the impact of the grants they receive (Kempner, 2013). The proposed framework suggests that EE-builders should look to transaction cost economics and studies of organizational costs to identify specific costs that could be measured and tracked over time. For instance, if regional leaders want to determine if their efforts at EE development have been successful, they could assess if entrepreneurs' costs of creating and operating businesses have decreased over time.

Our theory also emphasizes the important role that entrepreneurial support organizations, such as incubators, accelerators, small business development centers, and educational institutions, play in increasing EE coordination and lowering transaction costs. By offering educational programs, imparting common values, and hosting events, support organizations allow EE participants to network, to learn from one another, and to be exposed to the culture that guides interactions and, as we argued, is the foundation of EE coordination. Finally, our theorizing suggests that practitioners should acknowledge the importance of fostering a community logic (based on values such as trust, cooperation, and community-building). Encouraging these types of actions is important not only for creating a civil community but also for lowering entrepreneurs' costs.

\section{Directions for Future Research on Entrepreneurial Ecosystems}

The theory presented in this paper identifies the costs influenced by entrepreneurial ecosystems. To extend this research, work is needed to identify specific empirical instruments to measure these costs. This is a critical next step because our theory would suggest that one method for assessing how vibrant - and how coordinated - an EE is, is to assess its costreduction capabilities.

The cost-saving benefits of EEs do not occur without costs. However, studies generally do not consider the economic or community costs associated with building and maintaining an EE. For example, there are significant costs involved in establishing and operating incubators and accelerators (e.g., Kempner, 2013). To spur the development of EEs, local governments often invest in these organizations or in other attempts to promote entrepreneurial activity, such as the creation of "innovation districts" (cf. Katz \& Wagner, 2014). Future research is needed to assess the value of EEs by attempting to measure the costs associated with their creation and comparing those costs to estimates of their cost-savings to local entrepreneurs and other ecosystem participants.

Our theory focuses on the influence of EEs on entrepreneurs' costs to create and scale new ventures. However, entrepreneurs represent only one type of ecosystem participant. For instance, in coordinated EEs, investors' transaction and search costs may also be reduced as information flows more easily among participants than in regions with under-developed EEs. 


\section{PLACE-BASED ADVANTAGES IN ENTREPENEURSHIP}

Future research is needed to examine how a thriving EE may influence the costs of doing business for other types of ecosystem stakeholders, such as investors, suppliers, and support organization managers.

The theorizing in this paper focuses on the influence of vibrant, well-functioning EEs on entrepreneurs' costs. Yet, not all ecosystems are flourishing or fully developed. There are regions with EEs that are nascent, stagnant, or in decline (Roundy, 2017b). Indeed, thriving EEs, like Silicon Valley and London, are rare. If scholars examine the cost implications of being located in non-coordinated ecosystems, it may generate findings that are applicable to more typical cities and regions. Related to these points, important insights might be generated by scholars examining if there are negative influences on entrepreneurs' costs if EEs become too large or too vibrant. For example, trends in Silicon Valley suggests that growth in the ecosystem has been associated with concomitant increases in the costs of office space, wages, and housing (e.g., Gabbe, 2019). Long commuting times and traffic congestion also decrease the connections among EE participants, which can increase the costs for producers, suppliers, and customers (Audretsch \& Belitski, 2017; Breznitz \& Taylor, 2014). Thus, while ecosystem coordination will be associated with decreased transaction costs, it is important to determine if coordination may increase other costs, such as the financial costs of property and human capital. More generally, future research is needed on the non-transaction cost outcomes of EE coordination.

Another potential challenge of vibrant and highly coordinated ecosystems is that if they are environments ripe for entrepreneurial activity then this will increase the number of entrepreneurs in the ecosystem and, thus, increase the competition among entrepreneurs for resources. While some intra-ecosystem competition may be beneficial, one force in coordinated EEs that pushes back on unproductive forms of competition is the community logic which exists in coordinated ecosystems and emphasizes cooperation, trust, and community-building among ecosystem participants (cf. Roundy, 2017a). While a strong community logic will not eliminate competition among entrepreneurs in an EE, it will reduce self-seeking behaviors (cf. Feld, 2012 for an example).

Furthermore, one of the driving questions of transaction cost economics is, for a given transaction, are costs minimized in the marketplace (i.e., by using the price mechanism) or by internalizing the transaction in a firm? (David \& Han, 2004). Our theorizing suggests that EE participants face a "tripartite" decision: should they engage in a market transaction, internalize the transaction in their venture, or arrange the transaction through their entrepreneurial ecosystem? An exciting area for future research is to examine what exchanges are best relegated to each of the three transaction mechanisms.

Finally, for entrepreneurial ecosystems research to become a developed sub-discipline at the intersection of entrepreneurship, management, and economic development, it is necessary for scholars to formulate theories of the emergence, functioning, and influence of EEs. In this paper, we have taken the first steps toward developing a theory to explain how entrepreneurial ecosystems influence entrepreneurial activity by functioning as systems of cost-reducing mechanisms. We hope that this theory spurs future research examining the connections between entrepreneurial ecosystems and the entrepreneurship process. 


\section{PLACE-BASED ADVANTAGES IN ENTREPENEURSHIP}

\section{References}

Adner, R. (2017). Ecosystem as structure: an actionable construct for strategy. Journal of Management, 43(1), 39-58.

Adner, R., \& Kapoor, R. (2010). Value creation in innovation ecosystems: How the structure of technological interdependence affects firm performance in new technology generations. Strategic Management Journal, 31(3), 306-333.

Ahmad, R., \& Etudaiye-Muhtar, O. F. (2017). Dynamic model of optimal capital structure: Evidence from Nigerian listed firms. Global Business Review, 18(3), 590-604.

Amatucci, F. M., \& Swartz, E. (2011). Through a fractured lens: Women entrepreneurs and the private equity negotiation process. Journal of Developmental Entrepreneurship, 16(3), 333-350.

Audretsch, D. B., \& Belitski, M. (2017). Entrepreneurial ecosystems in cities: Establishing the framework conditions. The Journal of Technology Transfer, 42(5), 1030-1051.

Audretsch, D. B., \& Keilbach, M. (2008). Resolving the knowledge paradox: Knowledgespillover entrepreneurship and economic growth. Research Policy, 37(10), 1697-1705.

Auerswald, P. E., \& Dani, L. (2017). The adaptive life cycle of entrepreneurial ecosystems: The biotechnology cluster. Small Business Economics, 49(1), 97-117.

Autio, E., \& Levie, J. (2017). Management of entrepreneurial ecosystems. In G. Ahmetoglu, T. Chamorro-Premuzic, B. Klinger, \& T. Karcisky (Eds.). The Wiley Handbook of Entrepreneurship, 423-449. Chichester: John Wiley \& Sons

Bala Subrahmanya, M. H. (2017). How did Bangalore emerge as a global hub of tech start-ups in India? Journal of Developmental Entrepreneurship, 22(1), 1-22.

Braymen, C., \& Neymotin, F. (2014). Enclaves and entrepreneurial success. Journal of Entrepreneurship and Public Policy, 3(2), 197-221.

Breznitz, D., \& Taylor, M. (2014). The communal roots of entrepreneurial-technological growth-social fragmentation and stagnation: reflection on Atlanta's technology cluster. Entrepreneurship and Regional Development, 26(3-4), 375-396.

Brown, R., \& Mason, C. (2017). Looking inside the spiky bits: a critical review and conceptualisation of entrepreneurial ecosystems. Small Business Economics, 49(1), 1130.

Carmel, E., \& Nicholson, B. (2005). Small firms and offshore software outsourcing: high transaction costs and their mitigation. Journal of Global Information Management, 13(3), 33-54.

Cavallo, A., Ghezzi, A., \& Balocco, R. (2019). Entrepreneurial ecosystem research: present debates and future directions. International Entrepreneurship and Management Journal, forthcoming.

Chen, S. C. Y. (2010). Dimensions of Taiwanese entrepreneurship: Lessons from the world's top producer of touch fasteners. Global Business Review, 11(3), 333-345.

Coase, R. H. (1937). The nature of the firm. Economica, 4(16), 386-405.

Cunningham, J. A., Menter, M., \& Wirsching, K. (2019). Entrepreneurial ecosystem governance: a principal investigator-centered governance framework. Small Business Economics, 52(2), 545-562.

David, R. J., \& Han, S. K. (2004). A systematic assessment of the empirical support for transaction cost economics. Strategic Management Journal, 25(1), 39-58. 


\section{PLACE-BASED ADVANTAGES IN ENTREPENEURSHIP}

de Klerk, S., \& Saayman, M. (2012). Networking as key factor in Artpreneurial success. European Business Review, 24(5), 382-399.

Delmar, F., McKelvie, A., \& Wennberg, K. (2013). Untangling the relationships among growth, profitability and survival in new firms. Technovation, 33(8-9), 276-291.

den Butter, F. A., \& Linse, K. A. (2008). Rethinking procurement in the era of globalization. MIT Sloan Management Review, 50(1), 76-80.

Dias, A., \& Teixeira, A. A. (2017). The anatomy of business failure: A qualitative account of its implications for future business success. European Journal of Management and Business Economics, 26(1), 2-20.

Engel, J. S. (2015). Global clusters of innovation: Lessons from Silicon Valley. California Management Review, 57(2), 36-65.

Feld, B. (2012). Startup communities: Building an Entrepreneurial Ecosystem in Your City, Hoboken, NJ: John Wiley and Sons.

Feldman, M., Francis, J., \& Bercovitz, J. (2005). Creating a cluster while building a firm: Entrepreneurs and the formation of industrial clusters. Regional Studies, 39(1), 129-141.

Fiet, J. O., Norton Jr, W. I., \& Clouse, V. G. (2013). Search and discovery by repeatedly successful entrepreneurs. International Small Business Journal, 31(8), 890-913.

Gabbe, C. J. (2019). Local regulatory responses during a regional housing shortage: An analysis of rezonings in Silicon Valley. Land Use Policy, 80(1), 79-87.

Goldsby, M. G., Kuratko, D. F., Marvel, M. R., \& Nelson, T. (2017). Design-centered entrepreneurship: A four stage iterative process for opportunity development. Journal of Small Business and Entrepreneurship, 29(6), 477-490.

Goswami, K., Mitchell, J. R., \& Bhagavatula, S. (2018). Accelerator expertise: Understanding the intermediary role of accelerators in the development of the Bangalore entrepreneurial ecosystem. Strategic Entrepreneurship Journal, 12(1), 117-150.

Gulati, R., Puranam, P., \& Tushman, M. (2012). Meta-organization design: Rethinking design in interorganizational and community contexts. Strategic Management Journal, 33(6), 571-586.

Haines, T. (2016). Developing a startup and innovation ecosystem in regional Australia, Technology Management Innovation Review, 6(6), 24-32.

Halim, H. A., Ahmad, N. H., Ho, T. C., \& Ramayah, T. (2017). The outsourcing dilemma on decision to outsource among small and medium enterprises in Malaysia. Global Business Review, 18(2), 348-364.

Hochberg, Y. V. (2016). Accelerating entrepreneurs and ecosystems: The seed accelerator Model. Innovation Policy and the Economy, 16(1), 25-51.

Isenberg, D.J. (2010). How to start an entrepreneurial revolution, Harvard Business Review, 88(6), 40-50.

Jacobson, R. (1992). The Austrian school of strategy. Academy of Management Review, 17(4), 782-807.

Jarillo, J. C. (1989). Entrepreneurship and growth: The strategic use of external resources. Journal of Business Venturing, 4(2), 133-147.

Katz, B., \& Wagner, J. (2014). The rise of innovation districts: A new geography of innovation in America. Washington, DC: Brookings Institution.

Kempner, R. (2013). Incubators are popping up like wildflowers... but do they actually work? Innovations: Technology, Governance, Globalization, 8(3-4), 3-6. 


\section{PLACE-BASED ADVANTAGES IN ENTREPENEURSHIP}

Kerr, W. R., Nanda, R., \& Rhodes-Kropf, M. (2014). Entrepreneurship as experimentation. Journal of Economic Perspectives, 28(3), 25-48.

Ketokivi, M., \& Mahoney, J. T. (2016). Transaction cost economics as a constructive stakeholder theory. Academy of Management Learning and Education, 15(1), 123-138.

Khanin, D., \& Turel, O. (2016). CEOs' appraisals of venture capitalists' external and internal support: a transaction cost economics perspective. Venture Capital, 18(4), 297-320.

Korsgaard, S., Ferguson, R., \& Gaddefors, J. (2015). The best of both worlds: how rural entrepreneurs use placial embeddedness and strategic networks to create opportunities, Entrepreneurship and Regional Development. 27(9-10), 574-598.

Kuckertz, A. (2019). Let's take the entrepreneurial ecosystem metaphor seriously!. Journal of Business Venturing Insights, 11, e00124.

Kuratko, D. F., Fisher, G., Bloodgood, J. M., \& Hornsby, J. S. (2017). The paradox of new venture legitimation within an entrepreneurial ecosystem. Small Business Economics, 49(1), 119-140.

Lévesque, M., Minniti, M., \& Shepherd, D. (2009). Entrepreneurs' decisions on timing of entry: learning from participation and from the experiences of others. Entrepreneurship Theory and Practice, 33(2), 547-570.

Li, C., Isidor, R., Dau, L. A., \& Kabst, R. (2018). The more the merrier? Immigrant share and entrepreneurial activities. Entrepreneurship Theory and Practice, 42(5), 698-733.

Mack, E., \& Mayer, H. (2016). The evolutionary dynamics of entrepreneurial ecosystems. Urban Studies, 53(10), 2118-2133.

Malecki, E. J. (2018). Entrepreneurship and entrepreneurial ecosystems. Geography Compass, 12(3), 1-21.

Mason, C., \& Brown, R. (2014). Entrepreneurial ecosystems and growth oriented Entrepreneurship, Final Report to OECD, Paris, 30(1), 77-102.

Michael, S. C. (2007). Transaction cost entrepreneurship. Journal of Business Venturing, 22(3): 412-426.

Miles, M. P., \& Morrison, M. (2019). An effectual leadership perspective for developing rural entrepreneurial ecosystems. Small Business Economics, forthcoming, 1-17.

Motoyama, Y., \& Knowlton, K. (2017). Examining the connections within the startup ecosystem: A case study of St. Louis. Entrepreneurship Research Journal, 7(1), 1-32.

Muldoon, J., Bauman, A., \& Lucy, C. (2018). Entrepreneurial ecosystem: Do you trust or distrust?. Journal of Enterprising Communities: People and Places in the Global Economy, 12(2), 158-177.

Neck, H. M., Meyer, G. D., Cohen, B., \& Corbett, A. C. (2004). An entrepreneurial system view of new venture creation. Journal of Small Business Management, 42(2), 190-208.

Neumeyer, X., Santos, S. C., Caetano, A., \& Kalbfleisch, P. (2019). Entrepreneurship ecosystems and women entrepreneurs: A social capital and network approach. Small Business Economics, 53(2), 475-489.

Nicotra, M., Romano, M., Del Giudice, M., \& Schillaci, C. E. (2018). The causal relation between entrepreneurial ecosystem and productive entrepreneurship: A measurement $\mathrm{f}$ framework. The Journal of Technology Transfer, 43(3), 640-673.

Nylund, P. A., \& Cohen, B. (2017). Collision density: driving growth in urban entrepreneurial ecosystems. International Entrepreneurship and Management Journal, 13(3), 757-776.

Pérez-Nordtvedt, L., Payne, G. T., Short, J. C., \& Kedia, B. L. (2008). An entrainment-based 


\section{PLACE-BASED ADVANTAGES IN ENTREPENEURSHIP}

model of temporal organizational fit, misfit, and performance. Organization Science, 19(5), 785-801.

Roundy, P. T. (2016). Start-up community narratives: The discursive construction of entrepreneurial ecosystems. The Journal of Entrepreneurship, 25(2), 232-248.

Roundy, P. T. (2017a). Hybrid organizations and the logics of entrepreneurial ecosystems. International Entrepreneurship and Management Journal, 13(4), 1221-1237.

Roundy, P. T. (2017b). 'Small town' entrepreneurial ecosystems: Implications for developed and emerging economies. Journal of Entrepreneurship in Emerging Economies, 9(3), 238-262.

Roundy, P. T. (2019). Back from the brink: The revitalization of inactive entrepreneurial ecosystems. Journal of Business Venturing Insights, 12, e00140.

Roundy, P. T., Bradshaw, M., \& Brockman, B. K. (2018). The emergence of entrepreneurial ecosystems: A complex adaptive systems approach. Journal of Business Research, 86(1), $1-10$.

Roundy, P. T., Brockman, B. K., \& Bradshaw, M. (2017). The resilience of entrepreneurial ecosystems. Journal of Business Venturing Insights, 8, 99-104.

Rousseau, D. M. (1989). Psychological and implied contracts in organizations. Employee Responsibilities and Rights Journal, 2(2), 121-139.

Schäfer, S., \& Henn, S. (2018). The evolution of entrepreneurial ecosystems and the critical role of migrants. A Phase-Model based on a Study of IT startups in the Greater Tel Aviv Area. Cambridge Journal of Regions, Economy and Society, 11(2), 317-333.

Shane, S., \& Venkataraman, S. (2000). The promise of entrepreneurship as a field of research. Academy of Management Review, 25(1): 217-226.

Spigel, B. (2016). Developing and governing entrepreneurial ecosystems: the structure of entrepreneurial support programs in Edinburgh, Scotland, International Journal of Innovation and Regional Development. 7(2), 141-160.

Spigel, B. (2017). The relational organization of entrepreneurial ecosystems, Entrepreneurship Theory and Practice. 41(1), 49-72.

Spigel, B., \& Harrison, R. (2018). Toward a process theory of entrepreneurial ecosystems, Strategic Entrepreneurship Journal. 12(1), 151-168.

Stam, E. (2015). Entrepreneurial ecosystems and regional policy: a sympathetic critique. European Planning Studies, 23(9), 1759-1769.

Stam, E., (2018). Measuring entrepreneurial ecosystems, In A. O’Connor, E. Stam, F. Sussan, and D. B. Audretsch (Eds.), Entrepreneurial ecosystems. Springer: Cham, 173-197.

Stam, E., \& Spigel, B. (2016). Entrepreneurial Ecosystems. In Blackburn, R., De Clercq, D., Heinonen, J. and Wang, Z. (Eds). Handbook for Entrepreneurship and Small Business. London: SAGE.

Stam, E., \& Van de Ven, A. (2019). Entrepreneurial ecosystem elements. Small Business Economics, forthcoming.

Theodoraki, C., Messeghem, K., \& Rice, M. P. (2018). A social capital approach to the development of sustainable entrepreneurial ecosystems: an explorative study. Small Business Economics, 51(1), 153-170.

Thornton, P.H., Ocasio, W., \& Lounsbury, M. (2012). The institutional logics perspective: a new approach to culture, structure and process. Oxford, UK: OUP. 


\section{PLACE-BASED ADVANTAGES IN ENTREPENEURSHIP}

Uzzi, B. (1996). The sources and consequences of embeddedness for the economic performance of organizations: The network effect. American Sociological Review, 61(4), 674-698.

Uzzi, B. (1997). Social structure and competition in interfirm networks: The paradox of embeddedness. Administrative Science Quarterly, 42(1), 35-67.

Welter, F. (2011). Contextualizing entrepreneurship — conceptual challenges and ways forward. Entrepreneurship Theory and Practice, 35(1), 165-184.

Welter, F., Trettin, L., \& Neumann, U. (2008). Fostering entrepreneurship in distressed urban neighbourhoods. International Entrepreneurship and Management Journal, 4 2, 109-128.

Williamson, O. E. (1981). The economics of organization: The transaction cost approach. American Journal of Sociology, 87(3), 548-577.

Williamson, O. E. (1985). The economic institutions of capitalism: Firms, markets, relational contracting. New York, NY: Free Press.

Yang, X., Ho, E. Y. H., \& Chang, A. (2012). Integrating the resource-based view and transaction cost economics in immigrant business performance. Asia Pacific Journal of Management, 29(3), 753-772. 